\title{
“IN THE APOCRYPHA": METAFICCIÓN HISTORIOGRÁFICA, TESTIMONIO Y LA ESCRITURA DE UNA HISTORIA MARGINAL EN ALIAS GRACE, DE MARGARET ATWOOD* ${ }^{* 1}$
}

\author{
Pedro Carmona Rodríguez ${ }^{* *}$
}

\begin{abstract}
Resumen: La novela de Margaret Atwood Alias Grace (1996) rescribe el archivo histórico para hacer sitio en él a un relato marginal, la historia de la convicta canadiense de origen irlandés Grace Marks. Recurriendo a la metaficción historiográfica, Atwood dota de poder a Marks para que inscriba una visión marcada en términos de género sexual de aquellos acontecimientos que la condujeron a prisión como una de las asesinas de Thomas Kinnear y Nancy Montgomery.

Este artículo explora la autobiografía testimonial producida por Grace Marks como medio para deslegitimar las versiones documentales de su caso. La subjetividad de Marks, como autora y lectora de lo que se publicó sobre ella, alteran el registro oficial a través de un modo auto-reflexivo que impregna de forma similar sus palabras, la novela de Atwood y la escritura de historia y ficción. Así, la novela queda circunscrita en las corrientes metaficticias contemporáneas que rescriben los marcos del acto de enunciación, y como consecuencia, investigan las figuras del autor y lector y capacitan a éste en la producción de significado textual.
\end{abstract}

Palabras clave: metaficción historiográfica, Margaret Atwood, marginalidad histórica, narrativa canadiense.

Abstract: Margaret Atwood's novel Alias Grace (1996) rewrites the historical archive to make room in it for a marginal story, that of the Irish Canadian convict Grace Marks. Resorting to historiographical metafiction, Atwood empowers Marks to inscribe a gendermarked view of the events that led her to prison as one of the murderers of Thomas Kinnear and Nancy Montgomery.

This paper explores the testimonial autobiography produced by Grace Marks as a means to delegitimate the documentary versions of her case. Marks' subjectivity as author and reader of what has been issued on her, alter the official record. This is carried out through a self-reflexive mood that equally taints her words, Atwood's novel and the writing of history and story. Thus, the novel is circumscribed within the contemporary metafictional trends that restructure the frames of the act of enunciation, and, as a consequence, investigate the roles of author and reader and enable the latter in the production of textual meaning. Keywords: historiographical metafiction, Margaret Atwood, historical marginality, Canadian writing.

Fecha de recepción: abril 2004

Fecha de aceptación y versión final: febrero 2006

${ }^{1}$ Este artículo es parte del proyecto de investigación "Revisiones del canon en Canadá y Estados Unidos (1975-2000): literatura, cultura y género" (PI2002/045). Agradezco el apoyo económico prestado por la Dirección General de Universidades e Investigación del Gobierno de Canarias.

*** Profesor contratado, Escuela Universitaria de Turismo Iriarte, Universidad de La Laguna; $\bowtie$ pmcarmo@ull.es. 
Basada en el caso real de la inmigrante de origen irlandés Grace Marks, Alias Grace (1997a [1996]), de la escritora canadiense Margaret Atwood, produce una reconstrucción arqueológica de la figura de la convicta Grace Marks y deshace la labor detectivesca sobre uno de los asesinatos que conmocionó a la sociedad del Ontario nonogésimo. ${ }^{2}$ Declarada culpable del asesinato de su patrón, el caballero Tory Thomas Kinnear, y de su ama de llaves Nancy Montgomery, Marks, doncella de la casa Kinnear en 1843, teje su vida desde prisión, antes y después de los crímenes, para el psiquiatra Simon Jordan. La información de los periódicos de la época se yuxtapone en la novela a la narrativa autobiográfica y testimonial de Grace, y ésta a su vez a una voz que, en tercera persona, nos proporciona una visión de la intimidad mental del médico. Todas estas narrativas se superponen por su parte a otros testimonios sobre Grace y sobre los crímenes cometidos por ella en compañía del mozo de cuadras James McDermott: rimas, cartas entre especialistas en psiquiatría, entre abogados y las epístolas personales de Grace y Simon constituyen un collage de voces insertadas en el contexto histórico del Canadá del XIX, desde los tardíos años veinte hasta 1871. En esta fecha y después de veintiocho años en prisión, se produce la excarcelación de Marks que cruza por tercera vez el Lago Ontario tras su huida a Estados Unidos y su consecuente deportación a Canadá junto a McDermott. Ya al lado de su marido, benefactor y amor de juventud, Jamie Walsh, Marks escribe a Simon el relato de sus últimos meses, y en él abre una perspectiva de futuro para una nueva vida lejos de Ontario.

Como mucha de la ficción producida en Canadá en los años ochenta y noventa, la novela con la que Atwood se hizo con el Premio Giller es una metaficción historiográfica enmarcada en la revolución republicana que en 1837 lideró William Lyon Mackenzie (1795-1861) (Oullet 1990; Senior 1990). No obstante, la metaficción historiográfica, característica con la que Linda Hutcheon marca a fuego el posmodernismo canadiense (1988; 1989; 1992; Ankersmit 1989), sufre una vuelta de tuerca en la novela de Atwood, que a su vez se sabe consciente de la formulación teórica que la nutre. Si la metaficción historiográfica es una examen crítico y auto-reflexivo de los mecanismos por los que se narrativiza el pasado en el texto histórico, ahora sometido a una equiparación con el texto de ficción por causa de una similar formulación y diseminación del conocimiento (Walker 1979), en la novela de Atwood esa conciencia auto-crítica se extiende al texto autobiográfico. Éste es el púlpito desde el que desmitificar el pasado y la historia oficial con el fin de hacer sitio para la narrativa personal de un sujeto marginado en términos de género sexual, clase y hasta en función de su carencia de facultades mentales. La historia de Grace se revela sabedora de su papel como historia recreada, deja lugar a la falsedad y a la omisión, se preocupa por su circulación y hace hincapié en la intertextualidad que mantiene con otras versiones con las que compite por legitimidad. "Historiographic metafiction suggests that truth and falsity may indeed not be the right terms in which to discuss fiction", explica Linda Hutcheon para luego añadir, "[t]he interaction of the historiographic and the metafictional foregrounds the rejection of the claims of both

\footnotetext{
${ }^{2}$ Graham Hugann califica la novela de detectivesca, pero Alias Grace nunca aclara quién cometió los asesinatos y, como hacen muchas novelas posmodernas, desplaza esta cuestión (2001: 223). La indeterminación y la incertidumbre que sobrevuelan la identidad de Marks en el texto de Atwood contradicen la característica fundamental del whodunnit, una forma narrativa precisamente centrada sobre la identidad del criminal.
}

Odisea, $\mathrm{n}^{\circ}$ 7, ISSN 1578-3820, 2006, 45-58 
'authentic' representation and 'inauthentic' copy alike, and the very meaning of artistic originality is as forcefully challenged as is the transparency of historical referentiality" (1992: 109-110).

Este artículo analiza la producción del testimonio de Grace como enunciación que deslegitima la oficialidad documental. En su acción trasgresora Marks se erige con la palabra que el patriarcado le ha arrebatado y construye una historia que puede ser tan verdadera como falsa pero ciertamente discordante con la oficialidad y presumida objetividad aséptica del caso Marks. Entre historia, historiografía y testimonio autobiográfico, la novela de Atwood rompe las expectativas de todos estos géneros al someterlos a una auto-reflexividad implacable. Con todas las dudas acerca de su veracidad que la narración de Grace despierta, éstas pasan a un plano secundario quedando en suspenso por efecto de la interrelación que el pasado de la mujer tiene con su presente y con el de los acontecimientos que la rodean. Presente y pasado son textos que la Grace costurera une y pespunta en su texto alternativo. Desde su creatividad con la aguja y el hilo, Marks fabrica un tejido en el que inscribir u ocultar su historia marginal, pero desde el que revisa la tradición masculina de la escritura documental. La contraposición del texto que crea con aquellos que han circulado sobre ella abre un enclave de incertidumbre irreducible en el que se emborronan los límites entre versiones, discursos y figuras; entre verdad y mentira.

Alias Grace se implica directamente en la tendencia de la metaficción contemporánea a reestructurar los marcos del acto de enunciación en sí. Para ello genera un espacio ambiguo entre las figuras del autor y el lector, subrayando siempre el papel de éste en la producción del significado textual, así como "the discursive context of the writing and reading of the text" (Hutcheon 1988: 61). En la novela de Atwood, Grace se mueve oscilatoriamente entre lector y autor: lee lo que la opinión pública ha escrito sobre ella, expresa sus opiniones sobre esa producción atribuyéndole significados y, además, elabora un texto testimonial y memorístico que se concibe en muchos casos como una versión alternativa. Al recuperar auto-reflexivamente el entramado de producción del texto y su lectura, la novela de Atwood apunta directamente a la participación de múltiples subjetividades en la producción textual. Al convertir a Grace en lectora y escritora, autora de historia y de ficción por efecto de la metaficción historiográfica, la novela proporciona una doble visión de dos planos encontrados. El sujeto de Marks narrativiza una experiencia distinta, que, marcada genéricamente, se empeña en distanciarse de, y a veces en acercarse a, las versiones que Grace lee; no disfraza la falsedad ni los intereses personales, desplaza el centro de poder patriarcal que la ha marginado del documento histórico oficial y logra una desmitificación del hecho textual y del mismo pasado en tanto que tal.

La noción de intertextualidad paródica sin la cual la metaficción historiográfica es inconcebible fuerza un patrón de repetición del texto original con una diferencia básica que permite la delimitación del nuevo texto y su distanciamiento del texto base (Hutcheon 1989; Kuester 1992; Waugh 1990). La estrecha relación entre intertextualidad y parodia hace que la distinción entre ambas no esté siempre clara. Como afirma Kuester (1992: 14), parece lícito que la intertextualidad engloba varios modos, entre ellos la parodia y la metaficción, a su vez sometidas a una serie de subdivisiones y a zonas de solapamiento

Odisea, $\mathrm{n}^{\circ}$ 7, ISSN $1578-3820,2006,45-58$ 
conceptual (Bakhtin 1981; Hutcheon 1985; Slethaug 1997). ${ }^{3}$ En el marco del discurso posmoderno y del texto historiográfico, la parodia y la intertextualidad aparecen como un deseo de investigar en la fractura entre el pasado y el presente, como una voluntad de reescribir el pasado en un contexto actual (Hutcheon 1992: 118).

Desprovista de los constituyentes de burla, mofa y ridículo que fueron esenciales en la génesis del concepto aristotélico, la parodia posmoderna formula una relación de distancia y proximidad entre los textos relacionados en su ámbito, una relación profundamente irónica. Es esa la relación que existe entre la historia oficial del caso Marks y su ficcionalización en las páginas de Atwood, y entre la Biblia, por ejemplo, y sus versiones apócrifas o no autorizadas, tal y como Kinnear explica a Grace y Nancy en el transcurso de una escena de limpieza cotidiana. Al ver un grabado en la pared que Grace desconoce, Nancy la instruye diciendo que se trata de la historia de Susana y los Padres y que ésta se encuentra en la Biblia. Tras comprobar que Grace es incapaz de reconocer el episodio como parte de la mitología bíblica tradicional, es Kinnear quien informa que la historia es parte de la Apócrifa: "[t]hen he said the Apocrypha was a book where they'd put all the stories from Biblical times that they'd decided should not go into the Bible. I was most astonished to hear this, and I said, Who decided? [...]" (Atwood 1997a: 261). La interrogación de Grace acerca de quién dice qué narraciones se incluyen en el archivo coloca su historia y la de Susanah, la Biblia, el grabado en la sala de Kinnear y los documentos sobre Marks al mismo nivel.

The Collins Cobuild English Dictionary no recoge el término Apocrypha, pero aclara que apocryphal se aplica a una historia "not generally thought to be true or to have happened but which may convey a true picture of someone or something" (1995: 67). The Longman Dictionary of Contemporary English añade a esta acepción que el adjetivo se emplea para designar una historia "widely believed but probably untrue" (1990 [1978]: 37). De formas diferentes, ambas definiciones coinciden en destacar el contraste entre lo que se piensa falso y lo considerado verdadero, así como la posibilidad de lo verídico dentro de un marco de referencia plausible pero que despierta sospechas acerca de su veracidad. El relato de Grace se circunscribe en estos parámetros de indeterminación, pero llama la atención continuamente sobre su posible falsedad, ficcionalización de ciertos acontecimientos narrados, y por supuesto, sobre la narración como recreación alternativa con respecto a lo asumido por la voz popular y jurídica. Considerar la narrativa de Grace dentro de las posibilidades de ambigüedad semántica y significativa de lo apócrifo abre un espacio para la interrogación de los mismos conceptos de verdad y falsedad, y para

\footnotetext{
3 El posmodernismo de los años ochenta y noventa brinda un sinfín de ejemplos acerca de estos solapamientos conceptuales. Ellos son evidentes en novelas inglesas como The Passion (1988), Posession: A Romance (1990), Moon Tiger (1988), Waterland (1984), o Indigo, or Mapping the Waters (1993), de Janette Winterson, A.S. Byatt, Penelope Lively, Graham Swift y Marina Warner, respectivamente. En Canadá, The Wars (1977), de Timothy Findley, Burning Water (1980), de George Bowering, o Beautiful Losers (1972), de Leonard Cohen, son ejemplos de la complejidad que entraña la distinción entre metaficción y parodia. Por ello, términos como metaficción paródica o parodia metaficticia no son extraños en la crítica (Hutcheon 1988; 1992; Kuester 1992; Mathews 1989). Autores como Morson (1989) emplean el término metaparodia para referirse además a aquellas parodias que se saben conscientes de su condición y burlan elementos como la distancia crítica, produciendo confusiones entre el texto base y su secuela paródica.
}

Odisea, $\mathrm{n}^{\circ}$ 7, ISSN 1578-3820, 2006, 45-58 
considerar qué ha transcendido como lo uno y lo otro y su porqué. Asimismo, tal cuestionamiento deja al descubierto la actuación del poder en la consolidación de una narración como cierta o carente de verdad, el rol del narrador-historiador en esa construcción y, claro está, el papel de las estructuras de poder que respaldan a éste. Con ello queda constancia de que no existen discursos ciertos o no, sólo discursos con más poder que otros para afirmarse, tal y como sostiene Michel Foucault (1989). En la versión apócrifa de los acontecimientos, Grace da con la posibilidad de reconstruir su sujeto y en esa reconstrucción narrativa encuentra la vía de una agentividad social que le ha sido denegada por el discurso dominante y patriarcal.

Desde el comienzo de su narración, Grace es consciente de la existencia de mecanismos de poder a su alrededor. Esos mecanismos causan, por ejemplo, que habiendo sido juzgada junto a McDermott por el crimen de Kinnear, y ambos condenados a muerte, sólo él fuese ahorcado. ${ }^{4}$ Grace, sin embargo, recibe una conmutación de la pena de muerte por la cadena perpetua, hecho potenciado por su juventud -tiene escasos dieciséis años-y por su condición de mujer a la que se añade luego su aparente desequilibrio psíquico. Es en su estancia en la penitenciaría de Kingston, tras haber pasado por la cárcel de Toronto y un sanatorio mental en la misma ciudad, donde el comité para la excarcelación de Marks liderado por el reverendo Verringer pide la revisión del caso y nuevos informes sobre el estado mental de la reclusa. Se espera que la nueva evaluación, encargada al psiquiatra estadounidense Simon Jordan, revoque los diagnósticos desfavorables de las anteriores y abra la puerta de prisión a la que creen inocente. Con la llegada de Simon y en el curso de sus sesiones con él, Grace narra su vida y desde esa narración hace saber que se siente no sólo observada, sino que su vida ha sido escrita, distorsionada y leída. Para ella, mientras Simon hace de amanuense y toma nota de todo en un acto de representación biográfica, éste es el momento de reconstruir su imagen en el archivo y de lograr que ésta prevalezca.

En el transcurso de esas sesiones vemos a una Grace que se muestra encantada con la fama que ha alcanzado, una satisfacción que nunca revela a su psiquiatra pero que sí interioriza. Se sabe objeto de interés y poco parece importarle la causa por la que ha conseguido ser famosa o las penurias y humillaciones que el alguacil Smith, Tory reconocido, le inflingió tras su ingreso en prisión. ${ }^{5}$ De hecho, y a pesar de la enorme profusión de detalles con la que dota su narración, los crímenes casi no aparecen. Son, de veras o como parte de su imagen creada, un blanco en su memoria enferma de amnesia: "You should ask the lawyers and the judges, and the newspaper men, they seem to know my story better

\footnotetext{
${ }^{4}$ El crimen de Nancy Montgomery nunca llegó a juicio dado que los imputados por el doble asesinato fueron condenados a muerte por el homicidio de Kinnear. Tras su autopsia se descubrió que Montgomery estaba embarazada y durante el juicio de Kinnear salió a la luz que ya había sido madre soltera con anterioridad (Atwood 1997b). Muchas de estas informaciones se añadieron para desprestigiar a la mujer cuyo caso pasó inmediatamente a un plano secundario. Su género sexual, su vida amorosa y, no menos importante, su clase social se aliaron y confluyeron en la subordinación de su asesinato al suceso social que significó el de Thomas Kinnear.

5 Esas vejaciones, justificadas dentro de la causa política conservadora, son las que parecen haber ocasionado los períodos de demencia por los que Grace acaba en un sanatorio de Toronto. En uno de estos momentos de locura fue cuando recibió esa visita de Susana Moodie a la que Grace hace referencia. La descripción de Grace por boca de la propia Moodie la encontramos también en la novela (Atwood 1997a: 89-90).
}

Odisea, $\mathrm{n}^{\circ} 7$, ISSN 1578-3820, 2006, 45-58 
than I do myself", advierte Grace a Simon. "I can't remember, I can remember other things but I have lost that part of my memory" (Atwood 1997a: 45). Esa memoria sí mantiene el recuerdo por ejemplo, de las visitas que recibe, en especial de las de periodistas o escritores como Susanna Moodie. La impresión de conocer a la asesina más famosa del momento fue tal que, con una dramatización extrema y no muy ajustada a lo que vio, Moodie reflejó su encuentro en Life in the Clearings (1853), extractos del cual están dispersos por la novela dando una de esas muchas imágenes que Grace recoge con entusiasmo. Al comienzo del capítulo uno, y en el primero de esos extractos, Moodie reconoce que su visita a Kingston estuvo motivada por el interés en visitar a la que llama 'celebrated murderess', y en el curso de ese mismo capítulo Grace explica con tono egocéntrico: "the reason they want to see me is that I am a celebrated murderess. Or that is what has been written down. When I first saw it I was surprised because they say Celebrated Singer and Celebrated Poetess and Celebrated Spiritualist and Celebrated Actress. Murderess is a strong word to have attached to you", reflexiona Grace. "Sometimes at night I whisper it to myself: Murderess, Murderess. It rustles, like a taffeta" (Atwood 1997a: 23).

En estas ocasiones observamos a una reclusa evidentemente lectora e interesada en lo que dice de ella la prensa, consciente del alcance de su figura para la opinión popular y muy pendiente del daño que ha sufrido su imagen como mujer. Durante sus últimos tiempos en la prisión de Kingston, Grace goza de un régimen semi-abierto y trabaja como doncella en la casa del Gobernador. Su imagen de sí misma en un espejo le trae a la mente su compleja e incongruente representación en los textos que han llegado a sus manos durante los años de su condena, y su acto narcisista tiene mucho que ver con los que caracterizan a su narrativa igual de narcisista (Hutcheon 1985). Así, Grace afirma:

I think of all the things that have been written about me -that I am an inhuman female demon, that I am an innocent victim of a blackguard forced against my will and in danger of my life, that I was too ignorant to know how to act and that to hang me would be judicial murder, that I am very fond of animals, that I am very handsome with a brilliant complexion, that I have blue eyes, that I have green eyes, that I have red and also auburn hair, that I am tall and also not the average height, that I am well and decently dressed, that I robbed a dead woman to appear so, that I am brisk and smart about my work, that I am of a sullen disposition with a quarrelsome temper, that I have the appearance of a person rather above my humble station, that I am a good girl with a pliable nature and no harm is told of me, that I am cunning and devious, that I am soft in the head and little better than an idiot. And I wonder, how can I be all these different things at once. (Atwood 1997a: 23)

De forma simultánea a la Grace que cuenta su vida para Simon, hay otra Grace que desenmaraña su memoria y convierte los textos escritos sobre ella en intertextos de su narración, hasta el punto de que nunca es posible saber si cuenta lo que recuerda, o, por el contrario, reconstruye a partir de lo que lee: “I don't know why they are all so eager to be remembered", protesta Grace cuando no está contenta con lo que los diarios recogen sobre ella. "What good will it do then. There are some things that should be forgotten by everyone, and never spoken again", termina la joven. Su aceptación o negación de lo que el discurso de la prensa ha creado sufre un vuelco cuando la mayor parte de los periódicos coincide en

Odisea, $n^{\circ} 7$, ISSN 1578-3820, 2006, 45-58 
subrayar su relación de contubernio con McDermott: "A lot of it is lies. They said in the newspapers that I was illiterate, but I could read even then. [...] They did say some true things. They said I had a good character; and that was so, because nobody had taken advantage of me, although they tried. But they called James McDermott my paramour", recuerda una descontenta Grace que también enfatiza: "[...] I think it is disgusting to write such things down" (Atwood 1997a: 28).

La manipulación que su historia y su imagen sufre en la prensa es similar a la que ella misma lleva a cabo en la historia de su vida que construye para Simon. Su lectura y su narración oral están afectadas por un proceso de selección similar, de concesión de preeminencia a unos datos sobre otros, de ocultamiento por razones puramente interesadas. Esta dimensión de proceso en la construcción del archivo sitúa a Grace al nivel del historiador por estar ambos afectados por una parecida inversión de subjetividad en los textos de los que son escriptores (Barthes 1986: 145). La relación íntima e intertextual de la narración de Grace con los textos que lee sobre ella queda a la luz de forma explícita en varias ocasiones. Ella misma, Simon o el abogado defensor de Marks, MacKenzie, notan que las informaciones generadas sobre Grace salen a la superficie en lo que la convicta cuenta, revelando su papel de lectora. El abogado dice haber recurrido a los periódicos para corroborar los datos ofrecidos por Marks, a lo cual inquiere el psiquiatra Jordan: "[h]as it occurred to you that she may have derived her corroborative details from the same source? Criminals will read about themselves endlessly, if given the chance. They are as vain in that way as authors" (Atwood 1997a: 448).

Haciéndose cargo de ese papel de autora, en el desarrollo de sus charlas con Simon, Grace muestra en todo momento un extremo control de la información que facilita, selecciona elementos de su banco de datos personal y los ordena a su conveniencia. En esa operación pone orden en los acontecimientos antes de manufacturarlos como hechos. Como el historiador, Grace recurre a la formulación de una narración, en el sentido con el que Hayden White dota el término stories. Para él, "stories [...] have a discernible form (even when that form is an image of a state of chaos) which marks off the events contained in them from the other events that may appear in a comprehensible chronicle of the years covered in their unfoldings" (1993: 6). ${ }^{6}$ En su concepción de la historia como objeto verbal y como actividad de narrativización, White concluye que el historiador recurre a tres técnicas de explicación que denomina emplotment, argument e ideological implication. Aunque fijar los límites de cada una de ellas no es fácil, ya que la narración suele implicar las tres técnicas, sí parece que Grace traza su itinerario vital con un predominio de la primera de ellas, una atribución de significado a los datos históricos mientras explica en paralelo la historia contada. Siguiendo a Northrop Frye en su The Anatomy of Criticism (1957), White distingue cuatro formas dentro de la técnica de emplotment: el romance, la tragedia, la comedia y la sátira (1993: 7). Y lo cierto es que Grace parodia las cuatro en su testimonio a veces trágico, otras cómico, algunas satírico y casi siempre romántico, en el sentido de descenso y redención con el que ve el concepto Frye (1976), pero también en la

${ }^{6}$ Junto a White (1981a; 1981b; 1988; 1993), las voces de Fredric Jameson (1981), Jonathan Culler (1989) y Derek Attridge (1987), entre otros muchos, y desde distintas perspectivas han percibido el proceso narrativo de la historia como idéntico al de la ficción, situando a ambas narraciones a un nivel similar.

Odisea, $\mathrm{n}^{\circ} 7$, ISSN $1578-3820,2006,45-58$ 
acepción del romance como historia de amor. Para White, sin embargo, la única diferencia entre el historiador y el escritor de ficción es que el primero narrativiza hechos verídicos, una distinción que como Hutcheon ha visto (1988: 66), es insostenible. Los hechos tienen un referente en tiempo y espacio sólo aprehensible por medio de su textualización, equiparándose así a los hechos ficticios. Por tanto, la diferencia entre historiador y autor de ficción se ha desdibujado, y con ello en mente, Atwood destaca de Grace esta calidad de historiadora, historian y storyteller, cuando dice:

In my fiction, Grace too -whatever else she is- is a storyteller, with strong motives to narrate, but also strong motives to withhold; the only power left to her as a convicted and imprisoned criminal comes from a blend of two motives. What is told by her to an audience of one, Dr. Simon Jordan -who is not only a more educated person than she is, but a man, which gave him an automatic edge in the nineteenth century, and a man with the potential to be of help to her-is selective, of course. It is dependent on what she remembers; or is it what she says she remembers, which can be quite a different thing? And how can her audience tell the difference. (Atwood 1997b: 36)

El proceso por el que Grace construye su historia y su testimonio está fraguado en lo que Collingwood denominó una imaginación constructiva (1956: 241), o lo que es lo mismo, un ensamblaje forzado de coherencia sobre los hechos, y que implica un intento de posicionarse a sí misma y a su narración fuera de los límites del discurso ficticio. Con ello, Grace intenta desligar su historia veraz de las falsedades de la prensa. Sin embargo, cae en una falacia al pensar que su narración autobiográfica no está igualmente imbuida en un sistema de representación interesado. Su pretensión universalista adolece de la misma debilidad que la del discurso histórico tradicional, el no verse como una construcción parcial. Su narración intenta preservar al historiador del giro narrativo, tal y como hizo Collingwood. Éste cae por ello en un conservadurismo "[...] fully evident when, in comparing the task of the historian and that of the novelist or storyteller, he reasserts the conventional contrast" (Engler 1994: 23). La historiografía en general, y en la novela de Atwood en particular, adopta lo que Bernd Engler llama función simbólica. Con tal designación se refiere a la atención prestada a los procesos por los que, en la creación de la narración histórica, se reafirman los intentos de dar al historiador poder sobre la realidad y de dotar a ésta de orden (1994: 26). Así, "[...] if we come to regard historiography as an endeavour which makes sense of historical reality in the same sense writers of fiction make sense of it, i.e. by transforming what appears to be unintelligible and alien into something comprehensible and familiar", opina Engler, "then the traditional differentiation between history and fiction, the discourse of the real and the discourse of the imaginary becomes irrelevant" (1994: 27).

Desde una posición de oblicuidad con respecto al hecho histórico, Grace dice verdades y mentiras, pero también verdades ficticias. Son éstas, tal vez no ocurridas pero sí relacionadas con datos comprobables, las que logran esa posición a veces incómoda en la narración de su vida y de los crímenes. Como aparece en las confesiones que se incluyen en el texto, la histórica Marks reveló su participación en los crímenes, pero la Grace de Atwood lanza desde su testimonio que todo fue invención de sus abogados y de los

Odisea, $n^{\circ} 7$, ISSN 1578-3820, 2006, 45-58 
periodistas; que intervino junto a McDermott en los asesinatos coaccionada por él bajo amenaza de muerte. Con ello, Grace lucha por mantener un equilibrio entre los actos de escritura sobre ella y su narración oral. A pesar de ello, la contradicción y el desdicho planean sobre cualquier imposición de coherencia. Como consecuencia de que la novela desplace a las manos de la lectora Grace la producción de significado(s), y que éstos difieran en gran medida de lo archivado, queda constancia de la manipulación por su parte del texto oficial. Así se subraya además que la configuración de éste está basada también en la lectura y manipulación de datos implicadas en la transformación del acontecimiento en hecho. La misma manipulación se percibirá además en la representación de Grace que Simon hace en su esperado informe, texto al que no accedemos, pero de cuya existencia en proceso Grace da cuenta mientras narra. Se sabe biografiada en ese instante y expresa su preocupación por lo que transcenderá de esas charlas: "while he writes, I feel as if he is drawing me; or not drawing me, drawing on me -drawing on my skin- not with the pencil he is using, but with an old-fashioned goose pen [...]. As if hundreds of butterflies have settled all over my face, and are softly opening and closing their wings" (Atwood 1997a: 77-78).

El solapamiento entre versiones, cada una de ellas con su propio centro, impide la constitución del hecho histórico como centro único. Además, la intersección cambiante de todas estas versiones coadyuva en la preparación de un caldo de incertidumbre para injertar la reconstrucción de Marks propulsada desde su testimonio oral. Por un lado, las versiones de la inducción de los asesinatos contadas por Grace y McDermott se oponen totalmente. Grace afirma en su confesión que fue idea del criado; éste que Grace le ofreció sus favores sexuales a cambio de asesinar a Montgomery. A estas versiones se añaden las que dibujan a Marks como demente y las que traen al texto una imagen de la muchacha como fría y con conciencia de lo que hace en todo momento. En este sentido, la misma Grace contribuye a fomentar estas imágenes de teatralidad en todos sus actos narrativos. En el momento de recibir la visita de Simon y consciente de que su opinión puede valerle la excarcelación, Grace reflexiona: "I have a good stupid look which I have practised" (Atwood 1997a: 42). Y lo mismo ocurre con su fingimiento de locura temporal que, como sabemos, los periódicos que lee le llevan atribuyendo desde su juicio. "[...] A wild beast, the newspaper said. A monster. When they come with my dinner, I will put the slop bucket over my head and hide behind the door, and that will give them a fright". Con una conciencia completa del acto planeado, Grace afirma: "if they want a monster so badly, they ought to be provided with one" (Atwood 1997a: 36).

Por otro lado, la pluralización de centros a los que la historia se adscribe rompe la imagen de una narrativa única a favor del concepto de interdiscursividad. Con la pluralidad de discursos en torno a Grace, su sujeto se configura en movimiento entre ellos, y lo mismo sucede con su historia y con la historia personal que fabrica. Género, clase social, afiliación política y hasta su origen irlandés intervienen en el tratamiento del sujeto de Marks. ${ }^{7}$ El collage estructural de la novela revela esa disposición: su voz y la de Simon;

\footnotetext{
7 Frente al origen bajo-escocés de Kinnear, tanto Grace como Nancy y McDermott eran irlandeses y, aunque de confesión protestante, el sector Tory no tardó en equiparar su procedencia con el conflicto entre Irlanda e Inglaterra, y así lo piensa Grace (Atwood 1997a: 116). Como veremos más adelante, el origen de Grace influye notablemente en su textualización como sujeto marginal.
}

Odisea, $\mathrm{n}^{\circ} 7$, ISSN $1578-3820,2006,45-58$ 
textos de periódicos, rimas, poemas, confesiones jurídicas; grabados y patrones de diseño de las colchas que Grace elabora mientras narra.

En una interrelación directa entre lo textil y lo textual, como afirma Nancy K. Miller siguiendo a Barthes (1986: 271), los patrones de esos edredones que Grace elabora cuando teje su historia para Simon se injertan en el texto histórico como la inserción de una experiencia de género en un código que margina a Grace por su condición femenina. De acuerdo a ello, "the language of textiles tends to engender in the dominant discursive strategies of much contemporary literary criticism a metaphorics of femininity deeply marked by Freud's account of women and weaving" (Miller 1986: 271). Dentro de la tradición americana de Nueva Inglaterra y el este de Canadá, la elaboración de estos patrones requiere tres pasos conocidos como piecing, patchwork y quilting, la unión de pequeños fragmentos formando figuras geométricas, la combinación de éstas y, por último, la unión de los cuadros creados para constituir la colcha. Como dice Elaine Showalter, la influencia de estas labores de corte doméstico se traspasa a la ficción de mujeres del siglo XIX, como estructura y como motivo, y el paralelismo entre la creación del edredón y el acto de elaboración narrativa es evidente: de la articulación de la palabra a la combinación de éstas en oraciones, en historias, en imágenes que aporten unidad a sus narraciones (1986: 223).

Desde la confección de quince de estos patrones que estructuran Alias Grace en otras tantas secciones, Grace ahora como aventajada costurera, revela y oculta información en un texto claramente alternativo a los que se han escrito sobre ella. Su imagen no puede sino traer a la mente la de la mítica Filomela, quien burla la autoridad patriarcal con su tapiz y establece en él una comunicación distinta con su hermana Procne; una comunicación que escapa a la vigilancia de su cuñado y violador Tereo (Hurgan 1990). Como ella, Grace parece encontrar en su labor un código cuasi-secreto, una écriture couverture (Radka citada en Showalter 1986: 225), que burla la mirada de todos, principalmente la de Simon (Rogerson 1998: 6). En sus confecciones ha hallado además un código de comunidad femenina con una extensa simbología que pasa desapercibida a quienes no son familiares con un lenguaje variable y de infinidad de matices (Hedges 1982). No es coincidencia que Grace cuente su historia mientras cose, mientras une piezas de tela para formar figuras. Su historia fabricada de retales sigue el mismo diseño y genera una totalidad a partir de fragmentos desglosados de otros textos. De la misma forma que su testimonio es un trabajo de costura, sus colchas cuentan la historia de su vida, y como Rogerson ha detectado uniendo el proceso de creación de Grace y de Atwood, "the symbolic equivalence of the activities of assembling a patchwork and writing a literary text is virtually self-evident: a patchworker selects small pieces of fabric and sews them together to make a whole; and a writer begins with ideas or images and eventually produces a finished text" (1998: 13). La de Grace es, sin lugar a dudas, una historia apócrifa, de opresión genérica, pero también una que subraya en su carácter de metaficción su condición de historia creada:

It is morning and time to get up; and today I must go on with the story. Or the story must go on with me, carrying me inside it, along the track it must travel, straight to the end, weeping like a train and deaf and single-eyed and locked tight shut; [...]. When you are in the middle of a story it isn't a story at all, but only a confusion; a dark roaring, a blindness, a wreckage

Odisea, $n^{\circ} 7$, ISSN 1578-3820, 2006, 45-58 
of shattered glass and splintered wood; [...]. It is only afterwards that it becomes anything like a story at all. When you are telling it, to yourself or to someone else. (Atwood 1997a: 355)

A través de una labor tradicionalmente femenina como es la de la costura de las colchas, Grace revisa la tradición literaria e histórica masculina por medio de un testimonio vehicular. En él y en virtud de su costura, se representa a sí misma, oculta y revela información, busca escapatoria y se siente admirada como resultado de su tarea, una metáfora que la une a figuras míticas como la ya aludida de Filomela, Penélope o Aracne. La imagen de éstas, "the embroider that embroiders her own story" (1986: 286), dice Nancy K. Miller de Aracne, y su reflejo intertextual en Grace generan en la novela un mise en abyme recurrente: la costurera/autobiógrafa que representa su historia en su tejido-texto; éste formado por fragmentos de otros tejidos y concebido como réplica al texto histórico patriarcal. La narración de Grace, su testimonio y su labor de costura, son por igual un ejemplo de textualidad horizontal. No es sólo que cada cuadro de la colcha se vincule por puntadas al que está a su lado, que todos se encuentren unidos al elemento figurativo vecino, asociándose con él por una armonía de colores y formas, sino que cada texto que Grace inmiscuye en su narración a Simon muestra la misma disposición a encajar en su fábrica casi perfecta. Una consideración similar cabe en relación a la novela de Atwood, un tejido perfecto de colores y formas encajadas. Como Atwood, Grace es consciente de que emplea moldes ya habituales cuyo diseño varía para acomodarlo a su gusto, dejando claro el intento de reclamar sus derechos sobre su labor y sobre su historia. Una vez excarcelada, casada con Walsh y embarazada, escribe a Simon el relato de su vida en los meses en que no se han visto. En él le cuenta: "while I am sitting out in the verandah in the afternoon, I sew away at the quilt I am making. Although I've made many quilts in my day, this is the first one I have ever done for myself. It is a Tree of Paradise; but I am changing the pattern a little to suit my own ideas" (Atwood 1997a: 551; Murray 2001). Eso es precisamente lo que Grace ha hecho hasta la fecha, "change the pattern to suit [her] ideas". La misma transformación está presente en su historia con el fin de adecuarla a lo que Simon espera de ella, y al hacerlo no sólo se ha inscrito como texto y en el texto histórico, variando su representación de ella, sino que ha demostrado que toda representación se constituye como una serie de actos repetidos dentro de un sistema establecido. La intertextualidad de la historia de Grace le permite apropiarse de los elementos necesarios para inscribir paródicamente su diferencia.

Es precisamente en este contexto de revisión y rescritura en el que hay que localizar la relevancia de la metaficción historiográfica. La posibilidad de la reescritura, de la interpretación doble, desde el pasado y el presente, la intervención de la duda en el cuerpo de la tradición. A ella contribuye la inserción de la historia apócrifa en la narrativa consolidada. A esto hay que añadir que la metaficción historiográfica de Alias Grace consigue llamar la atención del lector sobre lo silenciado, sobre la sombra de la falsedad en la historia que ha adquirido difusión y subrayar los mecanismos implicados en la elaboración del texto y en la manufactura de los acontecimientos. Con su alegoría doble del acto de lectura y de producción textual, la novela de Atwood inquiere en los mecanismos por los cuales atribuimos significado al texto y hace de la incertidumbre creada en torno a Marks un arma con la que abrir un espacio para minar el poder de los discursos patriarcales que han

Odisea, $n^{\circ} 7$, ISSN 1578-3820, 2006, 45-58 
invertido su esfuerzo en deslegitimar las narrativas femeninas. Desde su testimonio, Marks recupera ese espacio, y la auto-reflexividad con la que lo hace convierte su texto y la novela de Atwood en lo que Engler denomina "arche-stories of the ironic or subversive type" (1994: 33; Ingersoll 2001). Esto es, historias que, empeñadas en endeudarse con la reconstrucción del pasado, acaban por evidenciar la futilidad de la reconstrucción. La metaficción, en tanto que narración, no puede sino participar de aquello que critica, y así ocurre en la novela de Atwood, donde texto, historia y sujeto se vuelven sobre sí mismos para señalar su condición textual, entrando como Marks, en una circularidad irresoluble. Desde ella el presente mira al pasado para mostrar, como afirma Atwood, que "the past no longer belongs only to those who lived in it; the past belongs to those who claim it" (Atwood 1997b: 39). En esa reclamación vale la pena encuadrar Alias Grace, siempre teniendo en cuenta que dotar de significado el pasado es entender el presente.

\section{REFERENCIAS BIBLIOGRÁFICAS}

ANKERSMit, F. R. 1989. "Historiography as Postmodernism”. History and Theory: Studies in the Philosophy of History 28.2: 138-153.

AtTRIDGe, D. 1987. "Language as History/History as Language: Saussure and the Romance of Etymology". Post-Structuralism and the Question of History. Eds. Derek Attridge, Geoff Benington \& Robert Young. Cambridge, MS: Cambridge U.P. 183211.

Atwood, M. 1997a (1996). Alias Grace. Toronto: Seal.

1997b. In Search of Alias Grace: On Writing Canadian Historical Fiction. Charles R. Bronfman Lecture. Ottawa, U. of Ottawa Press.

Bakhtin, M. 1981. The Dialogic Imagination: Four Essays. Ed. Michael Holquist. Trad. Caryl Emerson y Michael Holquist. Austin: U. of Texas Press.

BARthES, R. 1986 (1977). Image-Music-Text. Trad. Stephen Heath. Nueva York: Hill \& Wang.

Culler, J. 1989 (1982). On Deconstruction: Theory and Criticism after Structuralism. Londres: Routledge.

Collingwood, R.G. 1956 (1946). The Idea of History. Londres: Routledge.

ENGLER, B. 1994. "The dismemberment of Clio: fictionality, narrativity and the construction of historical reality in historiographic metafiction". Historiographic Metafiction in Modern American and Canadian Literature. Eds. Bernd ENGLER \& Kurt MüLLER. Paderborn: Ferdinand Schöningh. 13-33.

Foucault, M. 1989 (1972). The Archaeology of Knowledge. Trad. Alan Sheridan. Londres: Routledge.

FRYE, N. 1976. The Secular Scripture: A Study of the Structure of Romance. Cambridge, MS: Harvard U.P. 
HedGes, E. 1982. "The nineteenth-century diarist and her quilts". Feminist Studies 8: 293-299.

HugGan, G. 1990. "Philomela's retold story: silence, music and the post-colonial text". The Journal of Commonwealth Literature 25.1: 12-23.

Routledge.

. 2001. The Postcolonial Exotic: Marketing the Margins. Londres:

HutChEON, L. 1985. A Theory of Parody: The Teaching of Twentieth-Century Art Forms. Nueva York: Methuen.

1988. The Canadian Postmodern: A Study of English Canadian Fiction. Toronto: Oxford U.P.

1989. "Historiographic metafiction: Parody and the Intertextuality of History”. Intertextuality and Contemporary American Fiction. Eds. Patrick O’Donnell \& Robert Con DAvis. Baltimore, MD: The Johns Hopkins U.P. 3-32.

dres: Routledge.

INGERSOLL, E. G. 2001. "Engendering metafiction: textuality and closure in Margaret Atwood's Alias Grace". American Review of Canadian Studies 31.3: 385-401.

JAMESON, F. 1981. The Political Unconscious: Narrative as a Socially Symbolic Act. Ithaca: Cornell U.P.

Kuester, M. 1992. Framing Truths: Parodic Structures in Contemporary EnglishCanadian Historical Novels. Toronto: U. of Toronto Press.

Mathews, J. T. 1989. "Intertextual frameworks: the ideology of parody in John Barth". Intertextuality and Contemporary American Fiction. Eds. Patrick O'Donnell y Robert Con DAvis. Baltimore, MD: The Johns Hopkins U.P. 35-57.

Miller, N. K. 1986. "Arachnologies: The woman, the text and the critic". The Poetics of Gender. Ed. Nancy K. MiLler. Nueva York: Columbia U.P. 270-295.

Morson, G. S. 1989. "Parody, history and metaparody". Rethinking Bakhtin: Extensions and Challenges. Eds. Gary Saul Morson \& Caryl Emerson. Evanston, IL: Northwestern U.P. 63-86.

MurRAy, J. 2001. "Historical figures and paradoxical patterns: the quilting metaphor in Margaret Atwood's Alias Grace”. Studies in Canadian Literature 26.1: 65-74.

Ouellet, F. 1990. "The insurrections". Readings in Canadian History: PreConfederation. (2 vols.). Eds. R. Douglas Francis \& Donald B. Sмith. Toronto: Holt, Rinehart \& Winston. 322-336.

Rogerson, M. 1998. "Reading the patchworks in Alias Grace". The Journal of Commonwealth Literature 33.1: 5-22.

SENIOR, E. K. 1990. "Suppressing rebellion in Lower Canada: British military policy and practice, 1837-38". Readings in Canadian History: Pre-Confederation. (2 
vols.). Eds. R. Douglas Francis \& Donald B. Smith. Toronto: Holt, Rinehart \& Winston. 336-346.

Showalter, E. 1986. "Piecing and writing". The Poetics of Gender. Ed. Nancy K. MiLler. Nueva York: Columbia U.P. 222-247.

SincLaIR, J. et al., eds. 1995. The Collins Cobuild English Dictionary. Londres: HarperCollins Publishers.

Slethaug, G. E. 1997 (1995). "Parody”. Encyclopedia of Contemporary Literary Theory. Ed. Irena R. MAKARYK. Toronto: U. of Toronto Press. 603-605.

SuMmers, D. et al. eds. 1990 (1978). The Longman Dictionary of Contemporary English. Burnt Mill (Essex): Longman.

WALKER, D. D. 1979. “On the supposed frontier between history and fiction”. Crossing Frontiers: Papers in American and Canadian Western Literature. Ed. Dick HARRISON. Edmonton: U. of Alberta Press. 11-29.

Waugh, P. 1990 (1984). Metafiction: The Theory and Practice of Self-Conscious Fiction. Londres: Routledge.

Whiте, H. 1981a. "The value of narrativity in the representation of reality". On Narrative. Ed. W. J.T. Mitchell. Chicago: The U. of Chicago Press. 1-24.

1981b. "The narrativisation of real events". On Narrative. Ed. W.J.T. Mitchell. Chicago: The U. of Chicago Press. 249-254.

1988. Tropics of Discourse: Essays on Cultural Criticism. Baltimore MD: The Johns Hopkins U.P.

1993 (1973). Metahistory: The Historical Imagination in NineteenthCentury Europe. Baltimore, MD: The Johns Hopkins U.P. 